\title{
Preferences of ELT Learners in the Correction of Oral Vocabulary and Pronunciation Errors
}

\author{
Hale Yayla Ustaci ${ }^{1} \&$ Selami $\mathrm{Ok}^{2}$ \\ ${ }^{1}$ Honaz Vocational College, Pamukkale University, Denizli, Turkey \\ ${ }^{2}$ Faculty of Education, Pamukkale University, Denizli, Turkey \\ Correspondence: Selami Ok, Faculty of Education, Department of English Language Teaching, Pamukkale \\ University, Kınıklı 20070, Denizli, Turkey. Tel: 90-258-296-1027. E-mail: selamiok@pau.edu.tr
}

Received: January 27, 2014 Accepted: March 19, 2014 Online Published: March 27, 2014

doi:10.5539/hes.v4n2p29

URL: http://dx.doi.org/10.5539/hes.v4n2p29

\begin{abstract}
Vocabulary is an essential component of language teaching and learning process, and correct pronunciation of lexical items is an ultimate goal for language instructors in ELT programs. Apart from how lexical items should be taught, the way teachers correct oral vocabulary errors as well as those of pronunciation in line with the preferences of learners is a crucial issue on which a consensus should be reached. This present study aimed to explore the preferences of ELT learners in a Turkish university on the correction of oral vocabulary and pronunciation errors by their instructors. The data were gathered from 213 ELT students through a five-point Likert scale, the items of which were derived from the answers given by the students to the open-ended questions regarding the research question. The findings in our study reveal that instructors teaching various field courses including the skill courses in freshman level in ELT departments need to be sensitive towards the preferences of learners in the correction of oral vocabulary and pronunciation errors, and they should explore how the learners would prefer their errors to be corrected as this can enable them to treat such errors more effectively and facilitate the learning process.
\end{abstract}

Keywords: oral vocabulary errors, pronunciation, error treatment, ELT

\section{Introduction}

The main question regarding the errors learnes make is whether they should be allowed or handled wisely using common correction strategies or techniques. Without doubt, teachers can benefit from knowing the likely errors that learners make (Ellis, 2008), and all learners need their teachers' help in the correction process because, as Long (1996) stated, feedback provided through verbal interaction can facilitate L2 learning by connecting form and meaning; however, it should be noted that correction of errors can be done based on learners' preferences. For this reason, error correction strategies serve a research purpose in various language teaching contexts as a major field of interest for teachers and researchers.

It can be presumed that the situation may be a bit complicated in an ELT context in which students are trained to become English teachers, and at times it could be very different from an EFL and ESL context, but still many similarities can be observed. In this sense, whether to correct vocabulary and pronunciation errors or not and how to correct these errors have always been important issues for instructors teaching at ELT departments; thus, this is an area which needs to be investigated in the Turkish context so that suggestions can be put forward for more effective treatment of such errors.

Apart from private institutions, the language education system in state high schools in Turkey mainly focuses on grammar teaching, reading comprehension and vocabulary learning. Since students have very limited exposure to written and spoken language use, those attending an ELT department may have difficulty in language and vocabulary use and ultimately arrive at ELT departments with lots of problems in vocabulary use and pronunciation. Naturally, as ELT students see their instructors as the main source of corrective feedback, their preferences in the correction of vocabulary errors and pronunciation problems have to be known by instructors so that such errors could be better handled from the freshmen level through the senior year in an ELT program.

ELT learners typically make errors regarding grammar, vocabulary use and pronunciation. Two main types of errors do emerge specifically in the process: "global errors" and "local errors", the former occurring in a 
situation where an error affects overall sentence organization and hinders the meaning, causing misunderstanding or incomprehensibility in communication whereas the latter are those which affect single elements in a sentence and do not cause significant problems in communication or prevent us from conveying the meaning and message (Burt, 1975; Nystrom, 1983; Brown, 1987; Holunga, 1994; Ellis, 2008), and it is commonly known that it is the global errors which need to be corrected in many situations. From another perspective, Brown (1987, p. 194) noted that "many utterances are not clearly global or local, and it is difficult to discern the necessity for corrective feedback." Just to make it more specific, as Holunga (1994, p. 33) stressed, local errors may include, for example, agreement errors, misused or missing articles, noun/verb phrase errors; on the other hand, global errors may include such features as misused or missing connectors, lack of tense sequences, misuse of pronouns and other errors that affect the coherence and cohesion of the discourse. On top of the classification of errors as global and local, another classification of error types was provided by Lee (1990, p. 7), who described the errors as "grammatical (morpho-syntactic) errors, discourse errors, phonologically-induced errors (covering pronunciation and intonation) and lexical errors". Sabbagh (1995, p. 19) also attempted to identify error types and presented four types of errors: "lexical", "syntactic", "pronunciation" and "understanding". Lexical errors are related to the misusage of the words while syntactic errors deal with grammatical errors. Pronunciation errors cover incorrectly pronounced words, and finally, understanding type of errors refers to learners' incorrect interpretation of task instructions.

In order to give an appropriate feedback whenever an error was made, everyone involved in teaching a language would agree that errors should be understood and analyzed appropriately. Truscott (1999, p. 439) suggests that if the teacher is to provide effective feedback to errors, he/she should label the errors in an exact way first. However, difficult grammatical items may also be challenging for the teachers and may hinder the process of error correction. Moreover, a noisy learning environment and an imperfect intonation and pronunciation may be other obstacles for labeling the errors. Teachers may even correct the right usage because of unclear understanding that the teaching atmosphere causes.

Some scholars talk about explicit and implicit error correction. For instance, Campillo (2003, p. 210) explains the difference between explicit and implicit error correction, saying that the former means providing the right form soon after an error occurs while the latter suggests showing that a mistake has occurred and it needs to be corrected. Mangubhai (2006, p. 7) states that "isolated explicit error correction refers to those instances where a teacher corrects a student but does not focus attention on that particular error" and "does not have the characteristic of explicitness and therefore is not likely to be effective", and this suggests that "to make some changes to the language behaviour of students, error feedback may have to be over a sustained period of time." On the other hand, Vann, Meyer and Lorenz (1984) found that some academic faculty members were inclined to view all errors as equally serious, saying that "an error is an error" (Ellis, 2008, p. 57), so it needs to be corrected. However, learners' expectations from error correction and teachers' views may not match. In a study by Ancker $(2000$, p. 22$)$, it was found that $76 \%$ of the students expected their mistakes to be corrected saying that "otherwise they would not learn to speak English correctly", whereas $75 \%$ of the teachers reflected an agreement on the fact that errors should not always be corrected as students' confidence and motivation could be influenced negatively. Along with this, teachers' perceptions and preferences may differ in different contexts depending on the learners' and teachers' characteristics and ways of giving feedback. For instance, Sato (2003) discusses that teachers should choose errors to be corrected and should not focus on all errors as this may destroy motivation of the students, suggesting that critical errors be corrected and the others can be ignored.

Whether teachers' and students' preferences on error correction strategies or techniques match or not has always been a controversial issue for researchers. For instance, while teachers may favor self-discovery of errors by students, this may be rated low among students as they may come up with different preferences in error correction and pronunciation practice (Hanh, 2005). As Sullivan and Lingren (2002) pointed out, students tend to focus more on the correction of mistakes and problems than on developing learning techniques, such as self-assessment and reflection which will give them skills to become more autonomous learners. In this sense, how errors can be corrected may also depend on the activity used in class. For instance, if it is a pronunciation activity, it would be more appropriate to interrupt the students and correct the mistakes immediately. If teachers want to motivate students to make self-correction, plenty of time should be allocated, and in order not to destroy fluency, it would be better for teachers to give feedback at the end of an activity. Regarding this issue, Williams (2003, p. 2) recommended that "teacher-student conferencing" would be really a beneficial type of giving feedback as students could develop a better understanding of the problematic points in their performances, and it would be easier to follow some strategies in order to cope with errors. Therefore, teachers should find the balance between fluency and accuracy, and should not exaggerate the task of correcting mistakes, otherwise, as 
Loewen (2007) stated, too much error correction can also shift the primary focus from communication to linguistic forms.

Chen (2005, p. 58) conducted a research with three English instructors teaching speaking classes in Taiwan in order to analyze effective feedback and error treatment, and found that each teacher suggested correcting students' errors by using a variety of techniques. It was mentioned by the subjects that they did not prefer to correct most of the learners' errors as learners had negative feelings, such as embarrassment and anxiety when they were corrected in class. Furthermore, the subjects seemed to have a consensus that errors were natural parts of learning and need not be corrected every time, and they all agreed that errors of pronunciation were common among learners and such errors should not be ignored.

Students' preferences in error correction may also vary depending on the skills and activities, and as a consequence of this, they may have different views about various types of correction. The study by Kavaliauskiene et al. $(2009$, p. 2) focused on students' attitudes towards correction, and the results showed that although students preferred error correction for their writing performance, they did not like being corrected during speaking activities. On the other hand, Katayama (2007, p. 289) did a research about the attitudes of Japanese students in the US towards correction of errors and found that the students preferred the correction made by the teacher and enjoyed having their pragmatic errors corrected. They also preferred getting cues from their teachers so that they can correct their own errors. Similarly, Salikin (2001, p. 2) did a study with the junior students at the English Department in Jember University and found that the participants felt positive about error correction and expressed that they not only welcomed feedback from teachers, but also from their peers, and also reported that that they did not prefer to be interrupted very often. The students preferred their pronunciation mistakes to be corrected rather than their grammar mistakes.

Consequently, from both teachers' and students' point of view, error correction is a crucial issue and an important task in language teaching and learning process; however, better learning opportunities may occur if the correction styles of teachers are in harmony with the students' error correction preferences. Lightbown and Spada (1990) draw attention to "an acquisition rich environment", stressing that "the expansion of an error by means of a correction technique allows the teacher to treat the error through conversational exchanges, information adjustments and opportunities for repairing faulty language rather than a mere provision of the correct model." Hence, whatever kind of error learners make, as Brown (1987, p. 195) pointed out, "learners creatively operate on a second language-constructing either consciously or subconsciously, a system for understanding and producing utterances in the language"; therefore, "research on error correction methods is not at all conclusive on the most effective method or technique for error correction." And as Seligson (1997) recommended, "if we are too negative about errors, students will not say anything, so we need to be careful about how we react."

\section{Method}

This present study aimed at finding out the preferences of ELT students on the strategies used by the instructors in the correction of oral vocabulary and pronunciation errors. Therefore, the research question of the study was designed as follows:

- What are the preferences of ELT students in error correction strategies used by the instructors regarding oral vocabulary and pronunciation errors?

\subsection{Participants and Research Context}

The participants were comprised of 58 male (27.2\%) and 155 female (72.8\%) students out of 213 ELT students attending The Department of English Language Teaching at Pamukkale University, Denizli, Turkey. The questionnaire was given to 58 freshmen, 60 sophomore, 35 junior, and 60 senior students who were available when the questionnaire was administered. In our program, the students who show a low proficiency level have to attend the preparatory class for two terms. Our students take integrated skill-based courses and continue to develop themselves in language skills in the freshman year.

\subsection{Data Collection Instrument}

A five-point Likert scale was designed for this study to gather the data. The items were in a sequence such as "I strongly disagree (SD) (1)", "I disagree (D) (2)", "Not sure (NS) (3)", "I agree (A) (4)" and "I strongly agree (SA) (5)", and they were derived from the answers given by the students to the open-ended questions regarding the correction of oral vocabulary and pronunciation errors. Three experts from the field of ELT were asked to check the items and give feedback, and necessary alterations were made based on the comments. Overlapping items were combined and those which reduced the reliability were omitted after the pilot study. After 15 items 
were excluded from a pool of 60 items, the Cronbach Alpha co-efficient was calculated as $\mathbf{0 . 8 8 7}$ for the whole questionnaire ( $\mathrm{N}$ of items: 45 ). The questionnaire consisted of five different sections. The second section which specifically became the focus of this paper included eleven items, and aimed to explore the preferences of ELT learners on the error correction strategies used by the instructors in the treatment of oral errors in vocabulary use and pronunciation. The Cronbach Alpha co-efficient for this section was .763, indicating a quite satisfactory level of reliability (Özdamar, 1999).

\subsection{Data Collection and Analysis}

The data to this study were collected in the spring term in 2010-11 academic year from the students attending our ELT department. Data collection procedure was completed in a week's time. The students who were given the survey were told that the results would be used for research purposes and they should mark the choices in the scale as they believed, not as they felt. SPSS 17 software version was used in the analysis of the data. Frequencies and percentages were used for the presentation of the data in Table-1 through Table-11. And finally, the pencentages and mean scores were calculated for the data presented in Table- 12 revealing the overall tendencies of all the participants.

\section{Results}

Our research question focused on the preferences of the ELT learners on the correction of oral vocabulary and pronunciation errors by the instructors. The results in Table 1 through Table 11 were presented depending on the levels of the learners and percentages for each item in a sequence of importance, and Table 12 was formed in order to provide a wider perspective on the preferences of all learners regardless of the levels and to identify the most and least favourite correction strategies.

Table 1 shows the preferences of the ELT learners focusing on students' feelings during the correction of oral vocabulary/pronunciation errors.

Table 1. Percentages for Item 1: While instructors are correcting my oral errors related to vocabulary use, I prefer being corrected without hurting my feelings

\begin{tabular}{lcccccc}
\hline & $\mathrm{N}$ & $\mathrm{SD}$ & $\mathrm{D}$ & $\mathrm{NS}$ & $\mathrm{A}$ & $\mathrm{SA}$ \\
& & $\%$ & $\%$ & $\%$ & $\%$ & $\%$ \\
\hline Freshmen & 58 & 0 & 0 & 0 & $\mathbf{1 9}$ & $\mathbf{8 1}$ \\
Sophomore & 60 & 5 & 1.7 & 3,3 & $\mathbf{2 3 . 3}$ & $\mathbf{6 6 . 7}$ \\
Junior & 35 & 0 & 0 & 5,7 & $\mathbf{3 4 . 3}$ & $\mathbf{6 0}$ \\
Senior & 60 & 0 & 1.7 & 1,7 & $\mathbf{3 6 . 7}$ & $\mathbf{6 0}$ \\
TOTAL & 213 & 1.4 & 0.9 & 2,3 & $\mathbf{2 7 . 7}$ & $\mathbf{6 7 . 6}$ \\
\hline
\end{tabular}

As Table 1 shows, when the percentages in "I agree" and "I strongly agree" are considered together, $100 \%$ of the freshmen, $90 \%$ of the sophomore, $94.3 \%$ of the junior and $96.7 \%$ of the senior learners prefer their instructors to correct their vocabulary/pronunciation errors without hurting their feelings. When all the levels are taken into consideration, it is seen that $95.3 \%$ of all the participants agree with the item, indicating a very high level of sensitivity about the correction of oral vocabulary and pronuciation errors by their instructors without hurting their feelings.

Table 2 shows the preferences of the ELT learners for a correction style "explaining the difference between the words with similar meanings". 
Table 2. Percentages for Item 2: While instructors are correcting my oral errors related to vocabulary use, I prefer being corrected by explaining the difference between the words with similar meanings

\begin{tabular}{lcccccc}
\hline & $\mathrm{N}$ & $\mathrm{SD}$ & $\mathrm{D}$ & $\mathrm{NS}$ & $\mathrm{A}$ & $\mathrm{SA}$ \\
& & $\%$ & $\%$ & $\%$ & $\%$ \\
\hline Freshmen & 58 & 0 & 0 & 8.6 & $\mathbf{3 6 . 2}$ & $\mathbf{5 5 . 2}$ \\
Sophomore & 60 & 1.7 & 5 & 6.7 & $\mathbf{5 1 . 7}$ & $\mathbf{3 5}$ \\
Junior & 35 & 0 & 2.9 & 2.9 & $\mathbf{6 5 . 7}$ & $\mathbf{2 8 . 6}$ \\
Senior & 60 & 1.7 & 1.7 & 6.7 & $\mathbf{5 3 . 3}$ & $\mathbf{3 6 . 7}$ \\
TOTAL & 213 & 0.9 & 2.3 & 6.6 & $\mathbf{5 0 . 2}$ & $\mathbf{3 9 . 9}$ \\
\hline
\end{tabular}

As can be seen in Table 2, when the percentages in "I agree" and "I strongly agree" are taken together, 91.4\% of the freshmen, $86.7 \%$ of the sophomore, $94.3 \%$ of the junior and $90 \%$ of the senior learners prefer their instructors to correct their oral vocabulary errors by explaining the difference between the words with similar meanings. When all the participants in four levels are considered, it is seen that a very high percentage of the learners $(90.1 \%)$ prefer the instructors to correct their oral vocabulary errors in this way.

Table 3 shows the preferences of the ELT learners on the correction of a vocabulary/pronunciation error if it is a fossilized one.

Table 3. Percentages for Item 3: While instructors are correcting my errors, I prefer them to correct the error if it is a fossilized one

\begin{tabular}{lcccccc}
\hline & $\mathrm{N}$ & $\mathrm{SD}$ & $\mathrm{D}$ & $\mathrm{NS}$ & $\mathrm{A}$ & $\mathrm{SA}$ \\
& & $\%$ & $\%$ & $\%$ & $\%$ \\
\hline Freshmen & 58 & 0 & 5.2 & 0 & $\mathbf{2 9 . 3}$ & $\mathbf{6 5 . 5}$ \\
Sophomore & 60 & 3.3 & 10 & 16.7 & $\mathbf{3 5}$ & $\mathbf{3 5}$ \\
Junior & 35 & 0 & 2.9 & 5.7 & $\mathbf{3 4 . 3}$ & $\mathbf{5 1 . 7}$ \\
Senior & 60 & 1.7 & 8.3 & 6.7 & $\mathbf{3 8 . 3}$ & $\mathbf{4 5}$ \\
TOTAL & 213 & 1.4 & 7 & 7.5 & $\mathbf{3 4 . 3}$ & $\mathbf{4 9 . 8}$ \\
\hline
\end{tabular}

As presented in Table 3, when the percentages in "I agree" and "I strongly agree" are considered together, 94.8\% of the freshmen, $70 \%$ of the sophomore, $86 \%$ of the junior, $83.3 \%$ of the senior learners agree that their instructors should correct their vocabulary/pronunciation errors if they are fossilized. The freshmen are more sensitive about such errors than the other levels. If we look at the percentages of the sophomore, junior and the senior learners in "I strongly agree" category, it can be seen that the students become more sensitive about their fossilized vocabulary and pronunciation errors as the level goes up. When all the participants are considered together in "I agree" and "I strongly agree" categories, $84.1 \%$ of all the participants prefer their instructors to correct their fossilized errors.

Table 4 shows the preferences of the ELT learners for a correction style "teaching the correct form of the word with its synonyms". 
Table 4. Percentages for Item 4: While instructors are correcting my oral errors related to vocabulary use, I prefer them to teach the correct form of a word with its synonym

\begin{tabular}{lcccccc}
\hline & N & SD & D & NS & A & SA \\
& & $\%$ & $\%$ & $\%$ & $\%$ & $\%$ \\
\hline Freshmen & 58 & 1.7 & 3.4 & 6.9 & $\mathbf{4 1 . 3}$ & $\mathbf{4 6 . 6}$ \\
Sophomore & 60 & 0 & 5 & 18.3 & $\mathbf{5 1 . 7}$ & $\mathbf{2 5}$ \\
Junior & 35 & 0 & 11.4 & 22.9 & $\mathbf{3 7 . 1}$ & $\mathbf{2 8 . 6}$ \\
Senior & 60 & 1.7 & 10 & 18.3 & $\mathbf{4 3 . 3}$ & $\mathbf{2 6 . 7}$ \\
TOTAL & 213 & 0.9 & 7 & 16 & $\mathbf{4 4 . 1}$ & $\mathbf{3 1 . 9}$ \\
\hline
\end{tabular}

According to Table 4, when the percentages in "I agree" and "I strongly agree" are assessed together, $87.9 \%$ of the freshmen, $76.7 \%$ of the sophomore, $65.7 \%$ of the junior and $70 \%$ of the senior learners prefer their instructors to teach the correct form of a word with its synonym while correcting oral vocabulary errors. The freshmen seem to agree on the use of this strategy more than the other three levels and they have the highest percentage according to "I strongly agree" category. When all the participants are considered together in "I agree" and "I strongly agree" categories, $76 \%$ of all the learners prefer the instructors to teach the correct form of a word with its synonym while correcting oral vocabulary errors. This result indicates the importance of using synonyms in the process of correction of vocabulary errors in order to make it more permanent in students' minds.

Table 5 shows the preferences of the ELT learners on "being given enough time for self-correction or self-repair of oral vocabulary/pronunciation errors"

Table 5. Percentages for Item 5: While the instructors are correcting my oral vocabulary/pronunciation errors, I prefer being given enough time to correct them on my own

\begin{tabular}{lcccccc}
\hline & $\mathrm{N}$ & $\mathrm{SD}$ & $\mathrm{D}$ & $\mathrm{NS}$ & $\mathrm{A}$ & $\mathrm{SA}$ \\
& $\%$ & $\%$ & $\%$ & $\%$ & $\%$ \\
\hline Freshmen & 58 & 0 & 3.4 & 17.2 & $\mathbf{6 3 . 8}$ & $\mathbf{1 5 . 5}$ \\
Sophomore & 60 & 6.7 & 1.7 & 18.3 & $\mathbf{4 1 . 7}$ & $\mathbf{3 1 . 7}$ \\
Junior & 35 & 0 & 2.9 & 20 & $\mathbf{6 0}$ & $\mathbf{1 7 . 1}$ \\
Senior & 60 & 3.3 & 5 & 11.7 & $\mathbf{4 0}$ & $\mathbf{4 0}$ \\
TOTAL & 213 & 2.8 & 3.3 & 16.4 & $\mathbf{5 0 . 2}$ & $\mathbf{2 7 . 2}$ \\
\hline
\end{tabular}

As Table 5 indicates, when "I agree" and "I strongly agree" categories are taken together, $79.3 \%$ of the freshmen, $73.4 \%$ of the sophomore, $77.1 \%$ of the junior and $80 \%$ of the senior learners prefer their instructors to give them enough time to correct their errors by themselves while the instructors are correcting their oral vocabulary/pronunciation errors. As the percentages seem to be very close, it can be concluded that most of the learners prefer to be guided for the self-repair of such errors. When all the participants are considered together, $77.4 \%$ of them agree on self-correction of vocabulary/pronunciation errors.

Table 6 presents the percentages focusing on a correction strategy "taking notes of vocabulary errors during the class hour and correcting them at the end of the class individually". 
Table 6. Percentages for Item 6: While instructors are correcting my oral errors related to vocabulary use/pronunciation, I prefer them to take notes during the class and correct them at the end of the class individually

\begin{tabular}{lcccccc}
\hline & N & SD & D & NS & A & SA \\
& & $\%$ & $\%$ & $\%$ & $\%$ \\
\hline Freshmen & 58 & 5.2 & 13.8 & 22.4 & $\mathbf{3 4 . 5}$ & $\mathbf{2 4 . 1}$ \\
Sophomore & 60 & 1.7 & 5 & 20 & $\mathbf{4 3 . 3}$ & $\mathbf{3 0}$ \\
Junior & 35 & 0 & 11.4 & 14.3 & $\mathbf{4 0}$ & $\mathbf{3 4 . 3}$ \\
Senior & 60 & 3.3 & 3.3 & 13.3 & $\mathbf{3 6 . 7}$ & $\mathbf{4 3 . 3}$ \\
TOTAL & 213 & 2.8 & 8 & 17.8 & $\mathbf{3 8 . 5}$ & $\mathbf{3 2 . 9}$ \\
\hline
\end{tabular}

According to Table 6, when the percentages in "I agree" and "I strongly agree" are considered together, 58.6\% of the freshmen, $73.3 \%$ of the sophomore, $74.3 \%$ of the junior and $80 \%$ of the senior learners agree that their instructors should take notes during the class, and their vocabulary/pronunciation errors should be corrected individually at the end of a class. As the level progresses, this seems to be quite clear as a preference and need among the senior learners, and this finding indicates a rising sensitivity to this sort of individual correction. When the total percentages are considered, it can be seen that $71.4 \%$ of the participants in all levels prefer their instructors to use this strategy. This means that instructors should help students individually by taking notes of the vocabulary and pronunciation errors during the class and handle their problems in small sessions. Only, 17.8\% of all participants were unsure about this correction strategy.

Table 7 shows the preferences of the ELT learners for "correcting errors instantly if the learners use a word deteriorating the meaning".

Table 7. Percentages for Item 7: While instructors are correcting my oral errors related to vocabulary use, I prefer to be corrected instantly if I use a word deteriorating the meaning

\begin{tabular}{lcccccc}
\hline & $\mathrm{N}$ & $\begin{array}{c}\text { SD } \\
\%\end{array}$ & $\begin{array}{c}\mathrm{D} \\
\%\end{array}$ & $\begin{array}{c}\text { NS } \\
\%\end{array}$ & $\begin{array}{c}\text { A } \\
\%\end{array}$ & $\begin{array}{c}\text { SA } \\
\%\end{array}$ \\
\hline Freshmen & 58 & 3.4 & 5.2 & 10.3 & $\mathbf{5 1 . 7}$ & $\mathbf{2 9 . 3}$ \\
Sophomore & 60 & 8.3 & 8.3 & 18.3 & $\mathbf{4 8 . 3}$ & $\mathbf{1 6 . 7}$ \\
Junior & 35 & 2.9 & 2.9 & 11.4 & $\mathbf{4 8 . 6}$ & $\mathbf{3 4 . 3}$ \\
Senior & 60 & 0 & 15 & 15 & $\mathbf{4 5}$ & $\mathbf{2 5}$ \\
TOTAL & 213 & 3.8 & 8.5 & 14.1 & $\mathbf{4 8 . 4}$ & $\mathbf{2 5 . 4}$ \\
\hline
\end{tabular}

As can be seen in Table 7, when the percentages in "I agree" and "I strongly agree" categories are considered together, $81 \%$ of the freshmen, $65 \%$ of the sophomore, $82.9 \%$ of the junior and $70 \%$ of the senior learners prefer their instructors to correct their vocabulary errors instantly if they use a word deteriorating the meaning. According to the total percentages, it can be seen that $73.8 \%$ of all the participants agree on the use of this correction strategy.

Table 8 shows the preferences of the ELT learners for "warning and suggesting the student to check the usage of a word during the correction of oral vocabulary errors". 
Table 8. Percentages for Item 8: While instructors are correcting my oral errors related to vocabulary use, I prefer them to warn me and suggest me to check the usage of the word again"

\begin{tabular}{lcccccc}
\hline & N & SD & D & NS & A & SA \\
& & $\%$ & $\%$ & $\%$ & $\%$ & $\%$ \\
\hline Freshmen & 58 & 3.4 & 5.2 & 8.6 & $\mathbf{5 5 . 2}$ & $\mathbf{2 7 . 6}$ \\
Sophomore & 60 & 5 & 10 & $\mathbf{2 1 . 7}$ & $\mathbf{4 5}$ & $\mathbf{1 8 . 3}$ \\
Junior & 35 & 0 & 11.4 & 14.3 & $\mathbf{6 8 . 6}$ & $\mathbf{5 . 7}$ \\
Senior & 60 & 0 & 8.3 & $\mathbf{2 6 . 7}$ & $\mathbf{4 0}$ & $\mathbf{2 5}$ \\
TOTAL & 213 & 2.3 & 8.5 & 18.3 & $\mathbf{5 0 . 2}$ & $\mathbf{2 0 . 7}$ \\
\hline
\end{tabular}

As presented in Table 8, the junior learners rank the first in "I agree" category, whereas $21.7 \%$ of the sophomore and $26.7 \%$ of the senior learners are unsure about this correction strategy. When the percentages in "I agree" and "I strongly agree" are considered together, $82.8 \%$ of the freshmen, $63.3 \%$ of the sophomore, $74.3 \%$ of the junior and $65 \%$ of the senior learners agree that the instructors should warn and suggest them to check the usage of the word again while correcting oral vocabulary errors. According to these percentages, it can be concluded that the freshmen seem to need their instructors' help more than the participants in the other levels do whereas the senior learners seem to be a bit confused about this strategy. When all the levels are considered as a whole, $70.9 \%$ of all the participants agree on the use of this correction strategy whereas $10.8 \%$ of them seems to have a negative attitude.

Table 9 shows the preferences of the ELT learners on a teacher correction style "correcting vocabulary errors by having the learners repeat the sentence".

Table 9. Percentages for Item 9: While instructors are correcting my oral errors related to vocabulary use, I prefer being corrected by having me repeat the sentence

\begin{tabular}{lcccccc}
\hline & $\mathrm{N}$ & $\mathrm{SD}$ & $\mathrm{D}$ & $\mathrm{NS}$ & $\mathrm{A}$ & $\mathrm{SA}$ \\
& & $\%$ & $\%$ & $\%$ & $\%$ \\
\hline Freshmen & 58 & 5.2 & 5.2 & $\mathbf{1 9}$ & $\mathbf{4 4 . 8}$ & $\mathbf{2 5 . 9}$ \\
Sophomore & 60 & 8.3 & 8.3 & $\mathbf{1 8 . 3}$ & $\mathbf{4 5}$ & $\mathbf{2 0}$ \\
Junior & 35 & 0 & 11.4 & $\mathbf{1 4 . 3}$ & $\mathbf{6 2 . 9}$ & $\mathbf{1 1 . 4}$ \\
Senior & 60 & 10 & 11.7 & $\mathbf{1 8 . 3}$ & $\mathbf{3 6 . 7}$ & $\mathbf{2 3 . 3}$ \\
TOTAL & 213 & 6.6 & 8.9 & $\mathbf{1 7 . 8}$ & $\mathbf{4 5 . 5}$ & $\mathbf{2 1 . 1}$ \\
\hline
\end{tabular}

As Table 9 shows, when "I agree" and "I strongly agree" categories are considered together, $70.7 \%$ of the freshmen, $65 \%$ of the sophomore, $74.3 \%$ of the junior and $60 \%$ of the senior learners prefer the instructors to correct their oral vocabulary errors by having them repeat the sentence. When all the participants are considered together in "I agree" and "I strongly agree" categories, it is seen that $66.6 \%$ of all the learners prefer the use of this correction strategy. This lower percentage indicates that not all the ELT learners are in favor of correction of oral vocabulary errors by repeating a sentence showing the correct usage of a word.

Table 10 shows the preferences of students for the correction of pronunciation errors by providing phonetic transcription of a mispronounced lexical item. 
Table 10. Percentages for Item 10: While instructors are correcting my pronunciation errors, I prefer to be corrected using phonetic transcription

\begin{tabular}{lcccccc}
\hline & $\mathrm{N}$ & $\mathrm{SD}$ & $\mathrm{D}$ & $\mathrm{NS}$ & $\mathrm{A}$ & $\mathrm{SA}$ \\
& & $\%$ & $\%$ & $\%$ & $\%$ \\
\hline Freshmen & 58 & 8.6 & 6.9 & 15.5 & $\mathbf{4 4 . 8}$ & $\mathbf{2 4 . 1}$ \\
Sophomore & 60 & $\mathbf{6 . 7}$ & $\mathbf{1 5}$ & 35 & $\mathbf{3 3 . 3}$ & $\mathbf{1 0}$ \\
Junior & 35 & $\mathbf{8 . 6}$ & $\mathbf{5 . 7}$ & 25.7 & $\mathbf{4 8 . 6}$ & $\mathbf{1 1 . 4}$ \\
Senior & 60 & $\mathbf{1 . 7}$ & $\mathbf{1 5}$ & 21.7 & $\mathbf{3 0}$ & $\mathbf{3 1 . 7}$ \\
TOTAL & 213 & $\mathbf{6 . 1}$ & $\mathbf{1 1 . 3}$ & 24.4 & $\mathbf{3 8}$ & $\mathbf{2 0 . 2}$ \\
\hline
\end{tabular}

According to the data in Table 10, when "I agree" and "I strongly agree" categories are considered together, $68.9 \%$ of the freshmen, $43.3 \%$ of the sophomore, $60 \%$ of the junior and $61.7 \%$ of the senior learners prefer their instructors to correct the pronunciation errors using the phonetic transcription for the mispronounced word. The percentages for the sophomores indicate that they have enough experience of phonetic transcription as they do a lot of work on phonetic transcription in the Linguistics course. When all the participants are considered together, nearly a quarter of the participants $(24.4 \%)$ are unsure while $58.2 \%$ of them prefer their instructors to correct the pronunciation errors by providing phonetic transcription of the mispronounced word. According to the total percentages, we see that $61.7 \%$ of all participants consider this correction strategy important, meaning that they attach importance to the use of phonetic transcription to help them gain better pronunciation. $21.7 \%$ of the sophomores, $14.3 \%$ of the juniors and $16.7 \%$ of the senior learners are against or do not need the use of phonetic transcription in correcting pronunciation errors, which means that providing the students in this group with the correct pronunciation would be satisfactory.

Table 11 presents the preferences of the ELT learners on the correction of oral errors related to pronunciation by having them repeat the right pronunciation of the word.

Table 11. Percentages for Item 11: While instructors are correcting my pronunciation errors, I prefer to be corrected by repeating the correct pronunciation of a word

\begin{tabular}{lcccccc}
\hline & N & SD & D & NS & A & SA \\
& & $\%$ & $\%$ & $\%$ & $\%$ \\
\hline Freshmen & 58 & 5.2 & 6.9 & 8.6 & $\mathbf{4 1 . 4}$ & $\mathbf{3 7 . 9}$ \\
Sophomore & 60 & $\mathbf{1 1 . 7}$ & $\mathbf{1 5}$ & $\mathbf{2 1 . 7}$ & $\mathbf{4 1 . 7}$ & $\mathbf{1 0}$ \\
Junior & 35 & 2.9 & 8.6 & $\mathbf{2 0}$ & $\mathbf{4 8 . 6}$ & $\mathbf{2 0}$ \\
Senior & 60 & 3.3 & $\mathbf{2 6 . 7}$ & $\mathbf{2 6 . 7}$ & $\mathbf{2 8 . 3}$ & $\mathbf{1 5}$ \\
TOTAL & 213 & 6.1 & $\mathbf{1 5}$ & $\mathbf{1 9 . 2}$ & $\mathbf{3 9}$ & $\mathbf{2 0 . 7}$ \\
\hline
\end{tabular}

As Table 11 reveals, when we consider the percentages in "I agree" and "I strongly agree" together, $79.3 \%$ of the freshmen, $51.7 \%$ of the sophomore, $68.6 \%$ of the junior and $43.3 \%$ of the senior learners agree on the repetition of the correct pronunciation of a mispronounced word. As the percentages show, the freshmen appreciate teacher-oriented correction of pronunciation errors more than the other three levels, and the senior learners prefer this way of correction the least. The difference in percentages between the sophomore, the junior and the senior learners indicate that the ELT learners are becoming more conscious and sensitive about their pronunciation errors as the level progresses, and they do not need to repeat the right pronunciation of a word. In other words, they do not seem to enjoy this sort of correction. Yet, when all the participants are considered, we can see that more than half of the learners $(59.7 \%)$ still would like to be helped with this correction strategy.

Table 12 below presents the overall mean scores and percentages on the correction of oral vocabulary and pronunciation errors. 
Table 12. Overall mean scores and percentages for the preferences of ELT learners on the correction of oral vocabulary \& pronunciation errors

\begin{tabular}{|c|c|c|c|c|c|c|c|}
\hline $\begin{array}{l}\text { When I make oral vocabulary \& pronunciation errors, } \\
\text { I prefer the instructors ... }\end{array}$ & M & $\mathrm{N}$ & $\begin{array}{c}\text { SD } \\
\%\end{array}$ & $\begin{array}{l}\mathrm{D} \\
\%\end{array}$ & $\begin{array}{c}\text { NS } \\
\%\end{array}$ & $\begin{array}{l}\mathrm{A} \\
\%\end{array}$ & ${ }_{\%}^{\text {SA }}$ \\
\hline 1. to correct my errors without hurting my feelings & 4.59 & 213 & 1.4 & 0.9 & 2.3 & 27.7 & 67.6 \\
\hline $\begin{array}{l}\text { 2. to correct my errors explaining the difference between } \\
\text { the words with similar meanings }\end{array}$ & 4.26 & 213 & 0.9 & 2.3 & 6.6 & 50.2 & 39.9 \\
\hline 3. to correct my error if it is a fossilized one & 4.24 & 213 & 1.4 & 7 & 7.5 & 34.3 & 49.8 \\
\hline 4. to teach the correct form of a word with its synonym & 3.99 & 213 & 0.9 & 7 & 16 & 44.1 & 31.9 \\
\hline 5. to give me enough time to correct my errors on my own & 3.96 & 213 & 2.8 & 3.3 & 16.4 & 50.2 & 27.2 \\
\hline $\begin{array}{l}\text { 6. to take notes during the class and correct them at the } \\
\text { end of the class individually }\end{array}$ & 3.91 & 213 & 2.8 & 8 & 17.8 & 38.5 & 32.9 \\
\hline $\begin{array}{l}\text { 7. to correct my errors instantly if I use a word } \\
\text { deteriorating the meaning }\end{array}$ & 3.83 & 213 & 3.8 & 8.5 & 14.1 & 48.4 & 25.4 \\
\hline $\begin{array}{l}\text { 8. to warn me and suggest me to check the usage of the } \\
\text { word again }\end{array}$ & 3.78 & 213 & 2.3 & 8.5 & 18.3 & 50.2 & 20.7 \\
\hline 9. to correct my errors by having me repeat the sentence & 3.66 & 213 & 6.6 & 8.9 & 17.8 & 45.5 & 21.1 \\
\hline $\begin{array}{l}\text { 10. to correct my pronunciation errors by providing } \\
\text { phonetic transcription }\end{array}$ & 3.55 & 213 & 6.1 & 11.3 & 24.4 & 38 & 20.2 \\
\hline $\begin{array}{l}\text { 11. to correct my errors by having me repeat the right } \\
\text { pronunciation of a word }\end{array}$ & 3.53 & 213 & 6.1 & 15 & 19.2 & 39 & 20.7 \\
\hline
\end{tabular}

According to the data in Table 12, when all the participants in four levels are taken as a whole considering the mean scores as well as the percentages in "I agree" and "I strongly agree" together, correction of vocabulary/pronunciation errors without hurting student's feelings $(\mathrm{M}=4.59 ; 95.3 \%)$, correction of vocabulary errors by explaining the difference between the words with similar meanings ( $M=4.26 ; 90.1 \%)$, correction of a vocabulary/pronunciation error if it is a fossilized one $(\mathrm{M}=4.24 ; 84.1 \%)$, teaching the correct form of a word with its synonym $(M=3.99 ; 76 \%)$, giving the students enough time to correct their errors on their own $(M=3.96$; $77.4 \%$ ) seem to be the most favourite error correction strategies preferred by the ELT students at our department in the correction of their oral vocabulary/pronunciation errors.

On the other hand, taking notes during the class and correcting the errors at the end of the class individually $(\mathrm{M}=3.91 ; 71.4 \%)$, correction of an error instantly if a student uses a word that deteriorates the meaning $(\mathrm{M}=3.83$; $73.8 \%)$ and warning the students and suggesting them to check the usage of a word again $(\mathrm{M}=3.78 ; 70.9 \%)$ can be accepted as good strategies if used properly and approached positively by instructors.

Finally, correction of errors by having students repeat a sentence containing a misused or mispronounced word $(\mathrm{M}=3.66 ; 66.6 \%)$, correction of pronunciation errors providing phonetic transcription $(\mathrm{M}=3.55 ; 58.2 \%)$, and correction of pronunciation errors by having students repeat the correct pronunciation of a word $(\mathrm{M}=3.53 ; 59.7 \%)$ seem to be the least preferred error correction strategies by the ELT students at our department, but we can say that quite many students seem to like this sort of correction.

\section{Discussion and Conclusion}

This study specifically focused on the preferences of ELT learners in a Turkish university in the treatment of oral vocabulary and pronunciation errors. Our findings reveal that correction of vocabulary and pronunciation errors without hurting student's feelings, correction of vocabulary errors by explaining the difference between the words with similar meanings, correction of a vocabulary or pronunciation error if it is a fossilized one, teaching the correct form of a word with its synonym, and finally enabling and motivating the students to correct their errors on their own seem to be the most favourite error correction strategies preferred by the ELT students at our department in the correction of their oral vocabulary/pronunciation errors.

Initially, although the first one on the list does not seem to be like a strategy, a great majority of the participants $(95.3 \%)$ in our survey agree that their instructors should correct their oral vocabulary and pronunciation errors 
without hurting their feelings, indicating a high level of sensitivity about the correction of such errors; therefore, instructors teaching at ELT departments need to be cautious about the way they react to such errors. Secondly, correction of oral vocabulary errors by explaining the difference between the words with similar meanings, such as "advise", "recommend" and "suggest", or "provide" and "enable", or "too, also, as well" is also perceived as a useful strategy. In this sense, it would be useful to give students handouts showing the difference of such pairs of words. The Lexis course could be used to eliminate such questions in students' knowledge. Thirdly, the correction of fossilized vocabulary and pronunciation errors is perceived highly important by $84.1 \%$ of the participants in our study. Similarly, Salikin's (2001, p. 2) study including 89 third-year students at an English department revealed that the learners preferred their pronunciation errors to be corrected rather than grammatical errors. Fourthly, teaching the correct form of a word with its synonym seems to be a good strategy, though with a lower percentage and mean score. Finally, $77.4 \%$ of all participants prefer their instructors to give them enough time to correct their errors by themselves while the instructors are correcting their oral vocabulary/pronunciation errors (See Table 5). The preference of our ELT learners seems parallel with the results of a study carried out by McCormick et al. (2007, p. 2) who found that the students were able to determine and correct their oral errors regarding grammar, vocabulary and pronunciation. Johnson and Jackson (2006, p. 543) argue that teachers may not differentiate errors and mistakes, and tend to correct every wrong utterance. Such an implication may result in ineffective applications in class; that's why error correction methods may be disadvantageous for learners if the students cannot get their own responsibility for learning to realize their own errors. Harmer (2001) suggests that instructors can encourage learners to realize their own errors and mistakes so that they can self-correct themselves instead of emphasizing and criticizing their errors, and states that overcorrecting the learners' mistakes may hinder the communicative style of a task, yet correcting errors gently may help learners much. Lynch $(2008$, p. 2) also says that the most effective strategy for error correction is self-correction as learners can realize and learn from their mistakes. Hoque $(2008$, p. 3) also argues that helping to focus students' attention on errors through self-correction or peer correction can reduce reliance on the teacher, and this can encourage student autonomy. In short, they should be trained in this aspect of error correction.

The percentages show that $71.4 \%$ of all participants prefer their instructors to take notes during the class and correct their oral vocabulary/pronunciation errors at the end of the class individually. The percentage of agreement is the highest among the senior learners ( $80 \%$ ) for this item, indicating a high level of sensitivity. Donald (2010, p. 41) speaks of the reasons causing "learner reticence" in the ESL classroom and says that some learners may have fears of being misunderstood and being disgraced; hence, they may not like being corrected at the time of speaking in front of their peers, and if the instructor attempts to correct their oral vocabulary and pronunciation errors in such a case, some learners may abstain from speaking in class. However, if the instructor corrects oral vocabulary and pronunciation errors at the end of a class individually, the learners may feel safer in the learning environment. In a study in a Turkish university carried out by Salı (2000) who aimed to explore EFL teachers' oral error treatment behaviors in ELT speaking classes as well as teachers' and learners' perspectives on treatment of oral errors, it was found that the students had strong preferences when their oral errors were concerned. It was reported that the students did not want their teachers to ignore their errors, and that they found error treatment useful and necessary to learn a foreign language better. The students also expressed strong preferences for delayed error treatment, teacher and self-treatment.

Most of the ELT learners at our department seem to be sensitive about being corrected instantly. $73.8 \%$ of the participants agree that the instructors should correct the oral errors related to vocabulary use instantly if they use a word deteriorating the meaning. Also, $70.9 \%$ of the ELT learners in our study prefer their instructors to warn and suggest them to check the usage of a word again while correcting their oral vocabulary errors. The freshmen tend to prefer their instructors' help more than the participants in the other levels. In this sense, Kelly (2006, p. 3) suggests that "there is no simple answer to the question of when to correct. It will depend on many interrelated factors including learner sensitivity, learning situation, learning purpose or task type".

According to the results of our study, correction of error by having students repeat a sentence in order to correct a misused or mispronounced word $(\mathrm{M}=3.66 ; 66.6 \%)$, correction of pronunciation errors providing their phonetic transcription $(\mathrm{M}=3.55 ; 58.2 \%)$ and correction of pronunciation errors by having students repeat the correct pronunciation of a word $(\mathrm{M}=3.53 ; 59.7 \%)$ seem to be the least preferred error correction strategies by the ELT students at our department. Yet, it is interesting that quite many ELT students at our department see repetition of sentence as a beneficial way, though with a lower percentage. In Park's study $(2010$, p. 1), which included 160 adult ESL students at Northern California University, 53\% of the learners reported that repetition is a beneficial way of correcting errors. In addition, Amador (2008, p. 18) explored the preferences of 23 college students in error correction and found that the participants preferred their teacher to let them repeat the correct form of a 
mistake so that their speech could improve in a short time.

On the other hand, more than half of the students (58.2\%) need instructor's help using phonetic transcription for mispronounced words. The sophomores do quite a lot of work on phonetic transcription in their Linguistics Course in our program and $43.3 \%$ of them still need to be helped by providing phonetic transcription, whereas $35 \%$ of them are still unsure and $21.7 \%$ of them disagree on the use of phonetic transcription in the correction of misused or mispronounced words (See Table 10). Also, 59.7\% of all participants are in favor of the correction of pronunciation errors by having them repeat the right pronunciation of a word, which means that it should not be delayed. The freshmen (79.3\%) prefer this way of correction the most among the ELT learners in our program, which indicates a high level of dependence on their instructors (See Table 11). Katayama's $(2007$, p. 8) study included 588 EFL learners, and $63 \%$ of the participants preferred their pronunciation errors to be corrected through repetition.

As Skehan (1998) and Robinson (2001) suggest, learners can have different goals when performing in an L2, sometimes focusing on accuracy, sometimes on complexity, and on other occasions on fluency (In Ellis and Barkhuizen, 2005, p. 141). Along with this, Ellis and Barkhuizen say that "investigating learner language in terms of accuracy, complexity and fluency is a particular view of L2 proficiency" and makes the assumption that "learners may choose to priotize one aspect of the L2 over another". To this end, just to make an analogy, learners may priotize the use of certain correction strategies over others in a language classroom. Therefore, in a similar fashion, the preferences of learners in the correction of oral errors in vocabulary usage as well as pronunciation errors should be explored and taken into consideration throughout the process in an ELT context, and the correction strategies students favor, as revealed by this study and many others, need to be identified by the instructors for a more effective and successful treatment of errors so that teacher trainees can take them as model correction strategies or techniques and reflect into their own classroom experiences.

\section{References}

Amador, Y. A. (2008). Learner attitudes toward error correction in a beginners English class. Revista Comunicacion, 17(29), 18-28.

Ancker, W. (2000). Errors and corrective feedback: Updated theory and classroom practice. English Teaching Forum, 38(4), 20-24.

Brown, H. D. (1987). Principles of language learning and teaching (2nd ed.). Englewood Cliffs, NJ: Prentice Hall Regents.

Burt, M. K. (1975). Error analysis in the adult EFL classroom. TESOL Quarterly, 9, 53-63. http://dx.doi.org/doi:10.2035/358612

Campillo, P. A. (2003). An analysis of implicit and explicit feedback on grammatical accuracy. A Journal of English and American Studies, 27, 229-248.

Chen, C. J. (2005). Effective feedback and error treatment: EFL Guidance for Academic Leaders (Unpublished doctoral dissertation). The University of Montana, the USA.

Donald, S. (2010). Learning how to speak: Reticence in the ESL classroom. ARECLS, 7, 41-58.

Ellis, R. (2008). The study of second language acquisition (2nd ed.). Oxford: Oxford University Press.

Ellis, R., \& Barkhuizen, G. (2005). Analyzing learner language. Oxford: Oxford University Press.

Hanh, P. T. (2005). Learners' and teachers' preferences for classroom activities. Essex Graduate Student Papers in Language and Linguistics, 7(1), 159-179.

Harmer, J. (2001). The practice of English language teaching. Edinburgh: Pearson Education Limited.

Holunga, S. (1994). The Effect of metacognitive strategy training with verbalization on the oral accuracy of adult second language learners (Unpublished doctoral dissertation). University of Toronto, Canada.

Hoque, M. E. (2008). Error correction preferences in written work of higher secondary students in Bangladesh: An evaluation. Retrieved February 12, 2010, from http://teachyourselffrenchfast.net

Johnson, K., \& Jackson, S. (2006). Comparing language teaching and other-skill teaching: Has the language teacher anything to learn? System, 34, 532-546. http://dx.doi.org/doi: 10.1016/j.system.2006.08.002

Katayama, A. (2007). Japanese EFL students' preferences toward correction of classroom oral errors. Asian EFL Journal, 9(4), 289-305.

Kavaliauskiene, G., Kaminskiene, L., \& Anusiene, L. (2009). Classroom Practice: Error Correction at Tertiary Level. Kalbu studijos, 14, 1-9. 
Kelly, S. (2006). Error correction. Occasional Paper Series, 17. Auckland, New Zealand: AIS St Helens Centre for Research in International Education.

Lee, N. (1990). Notions of "error" and appropriate corrective treatment. Hong Kong Papers in Linguistics and Language Teaching, 14, 55-70.

Lightbown, P. M., \& Spada, N. (1990). Focus-on-form and corrective feedback incommunicative language teaching: Effects on second language learning. Studies in Second Language Acquisition, 12(4), 429-448. http://dx.doi.org/doi:10.1017/ S0272263100009517

Loewen, S. (2007). Error correction in the second language classroom. Clear News, 11(12), 1-7.

Long, M. H. (1996). The role of the linguistic environment in second language acquisition. In W. C. Ritchie, \& T. K. Bhatia (Eds.), Handbook of second language acquisition (pp. 413-468). NewYork: Academic Press.

Lynch, L. M. (2008). English language error correction - A key language skills development tool. Retrieved July 13, 2010, from http://www.EzineArticles.com

Mangubhai, F. (2006). What do we know about learning and teaching second languages: Implications for teaching. Asian EFL Journal, 8(3), 46-68. (September 2006 Conference Proceedings: Task-based Learning in the Asian Context)

McCormick, D. E., O’Neill, M. C., \& Siskin, C. B. (2007). The Self-correction of speech errors. Learn Lab. Pitsburgh Science of Learning Center. Retrieved from http://www.learnlab.org/research/wiki/index.php

Nystrom, N. (1983). Teacher-student interaction in bilingual classrooms: Four approaches to error feedback. In H. Seliger, \& M. Long (Eds.), Classroom-oriented research in second language acquisition. Rowley, Mass.: Newburry House.

Özdamar, K. (1999). Paket programlar ile istatistiksel veri analizi-1 (2nci Bask1). Eskişehir: Kaan Kitabevi.

Park, H. S. (2010). Teachers' and learners' preferences for error correction (Unpublished master's thesis). California State University, Sacramento, California, the USA.

Robinson, P. (2001). Text complexity, task difficulty, and task production: Exploring interactions in a componential framework. Applied Linguistics, 22(1), 27-57. http://dx.doi.org/doi:10.1093/applin/22.1.27

Sabbagh, S. L. (1998). Learners' reactions to feedback in an adult ESL classroom (Unpublished master's thesis). California State University, the USA.

Salı, P. (2000). A study on treatment of oral errors in ELT classes (Unpublished master's thesis). Uludağ University, Bursa, Turkey.

Salikin, H. (2001). Learner's perception of oral error correction: An interpretive study. JIBS (Jurnal Ilmn Bahasa dan Sastra), 1(2).

Sato, K. (2003). Improving our students' speaking skills: Using selective error correction and group work to reduce anxiety and encourage real communication. Retrieved September 27, 2013, from http://files.eric.ed.gov/fulltext/ED475518.pdf

Seligson, P. (1997). Helping students to speak. London: Richmond Publishing.

Skehan, P. (1998). A cognitive approach to language learning. Oxford: OxfordUniversityPress.

Sullivan, K., \& Lindgren, E. (2002). Self-assessment in autonomous computer-aided second language writing. ELT Journal, 56(3), 258-266. http://dx.doi.org/doi: 10.1093/elt/56.3.258

Truscott, J. (1999). What's wrong with oral grammar correction. Canadian Modern Language Review, 55, 437-456. http://dx.doi.org/doi:10.3138/cmlr.55.4.437

Vann, R., Meyer, D., \& Lorenz, F. (1984). Error gravity: A study of faculty opinion of ESL errors. TESOL Quarterly, 18, 427-440. http://dx.doi.org/10.2307/3586713

Williams, J. G. (2003). Providing feedback on ESL students' written assignments. The Internet TESL Journal, 9(10). Retrieved February 20, 2010, from http://www.iteslj.org/Techniques/Williams-Feedback.html

\section{Copyrights}

Copyright for this article is retained by the author(s), with first publication rights granted to the journal.

This is an open-access article distributed under the terms and conditions of the Creative Commons Attribution license (http://creativecommons.org/licenses/by/3.0/). 